\title{
Absolute Quantitation of Stevioside and Rebaudioside A in Commercial Standards by Quantitative NMR
}

\author{
Atsuko Tada, ${ }^{* a}$ Kana Takahashi, ${ }^{a}$ Kyoko Ishizuki, ${ }^{a}$ Naoki Sugimoto, ${ }^{a}$ Takako Suematsu, ${ }^{b}$ \\ Kazunori Arifuku, ${ }^{c}$ Maiko Tahara, ${ }^{a}$ Takumi Akiyama, ${ }^{a}$ Yusai Ito, ${ }^{a}$ Takeshi Yamazaki, ${ }^{a}$ \\ Hiroshi Akiyama, ${ }^{a}$ and Yoko Kawamura ${ }^{a}$ \\ ${ }^{a}$ National Institute of Health Sciences; 1-18-1 Kamiyoga, Setagaya-ku, Tokyo 158-8501, Japan: ${ }^{b}$ JEOL RESONANCE

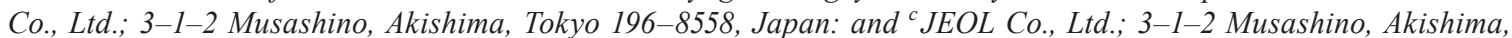 \\ Tokyo 196-8558, Japan. \\ Received August 20, 2012; accepted October 18, 2012; advance publication released online November 1, 2012
}

\begin{abstract}
The extract prepared from the leaves of Stevia rebaudiana BERTONI (Asteraceae) contains sweet steviol glycosides, mainly stevioside and rebaudioside A. Highly purified stevia extracts have become popular worldwide as a natural, low-calorie sweetener. They contain various types of steviol glycosides, and their main components are stevioside and rebaudioside $A$. The content of each steviol glycoside is quantified by comparing the ratios of the molecular weights and the chromatographic peak areas of the samples to those of stevioside or rebaudioside A standards of the Food and Agriculture Organization of the United Nations (FAO)/ World Health Organization (WHO) Joint Expert Committee on Food Additives (JECFA) and other specifications. However, various commercial standard reagents of stevioside and rebaudioside $A$ are available. Their purities are different and their exact purities are not indicated. Therefore, the measured values of stevioside and rebaudioside A contained in a sample vary according to the standard used for the quantification. In this study, we utilized an accurate method, quantitative NMR (qNMR), for determining the contents of stevioside and rebaudioside $A$ in standards, with traceability to the International System of Units (SI units). The purities of several commercial standards were determined to confirm their actual values.
\end{abstract}

Key words stevioside; rebaudioside A; quantitative NMR; absolute quantitation

The extract produced from the leaves of Stevia rebaudiana BERTONI (Asteraceae) contains sweet steviol glycosides, mainly stevioside and rebaudioside A (Fig. 1), and has long been used as a sweetener in Japan. In 2008, the specifications for "steviol glycosides" were established by the Food and Agriculture Organization of the United Nations (FAO)/World Health Organization (WHO) Joint Expert Committee on Food Additives (JECFA), and "stevia extracts" were approved as generally recognized as safe (GRAS) by the U.S. Food and Drug Administration (FDA). Thereafter, the purified stevia extracts specified in JECFA and FDA became popular worldwide.

According to the assay for steviol glycocides in the JECFA specifications, ${ }^{1)}$ the total content of nine types of steviol glycosides (Fig. 2) should not be less than 95\%. In the assay method, rebaudioside $\mathrm{A}$ is quantified from the peak area on LC using the rebaudioside A standard, and each steviol glycoside except rebaudioside $\mathrm{A}$ is quantified from their respective peak areas and absorption coefficients using the stevioside standard as the quantification standard.

Various commercial standard reagents of stevioside and rebaudioside A are available, although their purities are different and their exact purities are not indicated in the product literatures. Therefore, if the claimed values are employed in the quantitative analysis of a sample, the quantitated contents of the stevioside and rebaudioside $\mathrm{A}$ in the identical sample will be assigned different measured values according to the standard used for the quantification.

Quantitative NMR (qNMR) using an internal standard with traceability to the International System of Units (SI units) has recently been used to determine the absolute purities of various chemical substances. ${ }^{2-7)}$ The qNMR method permits the

The authors declare no conflict of interest. absolute quantification of a target compound without the need for a standard of that compound. In addition, it is rapid and easy. The compound is quantified from the ratios of the integral values of the proton signals of the internal standard and the target compound. In addition, various compounds can be quantified using the same internal standard.

In this study, we utilized the qNMR method to determine the purity of stevioside and rebaudioside $\mathrm{A}$ in commercial standards. The knowledge of their absolute purities will increase the accuracy of other analytical methods that use standards, such as LC.

\section{Experimental}

Reagents for qNMR Pyridine- $d_{5}$ (99.5 atom\% D) was purchased from Isotec (Ohio, U.S.A.). 1,4-Bis(trimethylsilyl)benzene- $d_{4}\left(1,4-\mathrm{BTMSB}-d_{4}\right)$ reference material (Wako Pure Chemical Industries, Ltd., Osaka, Japan; CAT No. 021-16441, Lot 081204; purity 99. $8 \pm 0.2 \%$ ) was used as an internal standard for NMR measurements. Diethyl phthalate (DEP), a certified reference material (CRM) of the National Metrology Institute of Japan (NMIJ) (NMIJ CRM 4022-b), was purchased from Wako Pure Chemical Ind., Ltd.; its purity is certified to be $99.98 \pm 0.09 \%$.

Stevioside and Rebaudioside A Standards Five stevioside standards were purchased: STD-I: Wako Pure Chemical Ind., Ltd., CAT No. 196-08131; STD-II: Wako Pure Chemical Ind., Ltd., CAT No. 193-15351, purity 99.0+\% (LC, dried); STD-III: Kanto Chemical (Tokyo, Japan), CAT No. 37480-92, purity $>98.0 \%$ (LC); STD-IV: USP (Maryland, U.S.A.), CAT No. 1622408: purity $0.97 \mathrm{mg} / \mathrm{mg}$ (not dry); and STD-V: ChromaDex (California, U.S.A.), CAT No. ASB-00019351-010: purity $98.4 \%$ (LC). Five rebaudioside A standards were also purchased: RBDA-I: Wako Pure Chemical Ind., Ltd., CAT No. 


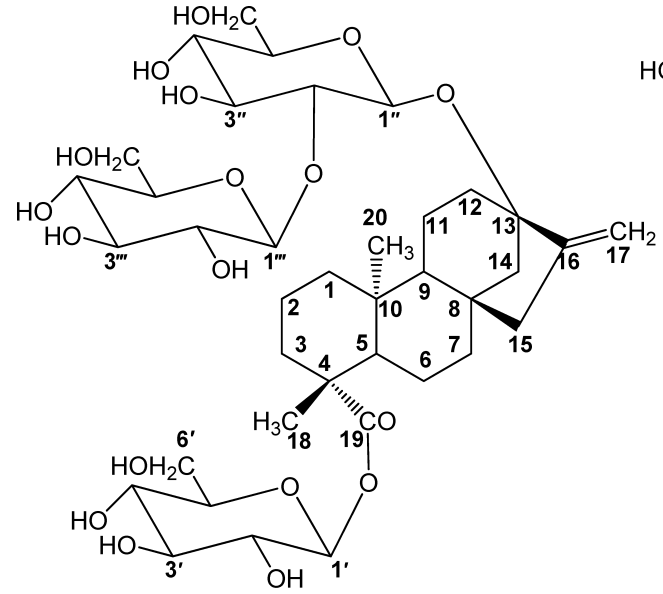

Stevioside

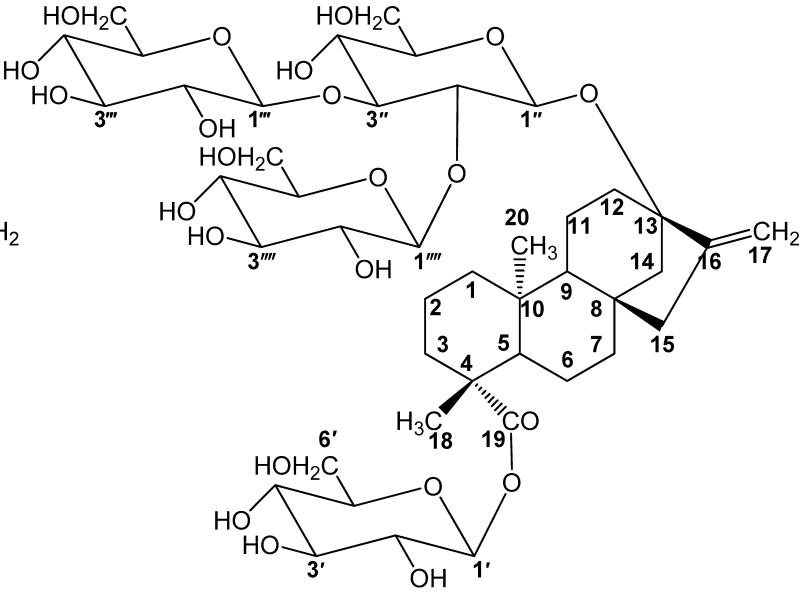

Rebaudioside A

Fig. 1. Structure of Stevioside and Rebaudioside A

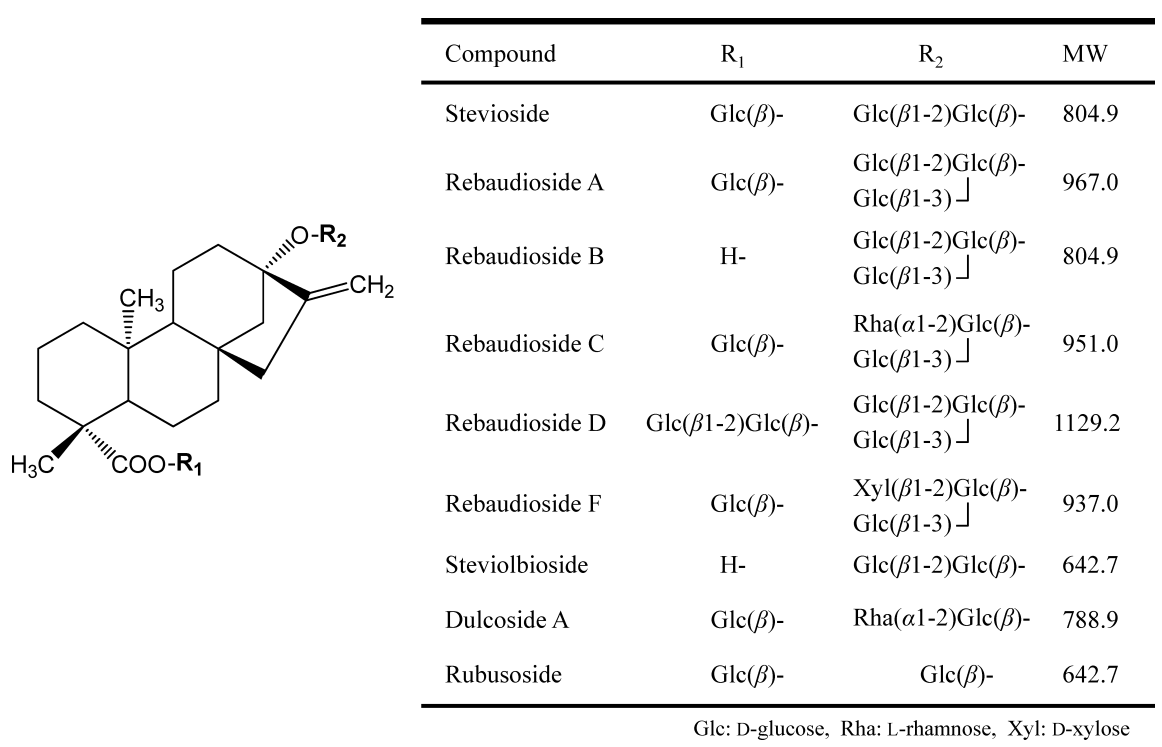

Fig. 2. Structures and Molecular Weights of Steviol Glycosides

186-00651; RBDA-II: Wako Pure Chemical Ind., Ltd., CAT No. 183-02361, 99.0+\% (LC, dried); RBDA-III: USP, CAT No. 1600121 , purity $0.969 \mathrm{mg} / \mathrm{mg}$ (not dry); RBDA-IV: ChromaDex, CAT No. ASB-00018225-050; and RBDA-V: ChromaDex, CAT No. ASB-00018226-010, purity 96.8\% (LC).

${ }^{1}$ H-NMR Spectrometer and Parameters ${ }^{1} \mathrm{H}-\mathrm{NMR}$ spectra were recorded on a JEOL JNM-ECA600 $(600 \mathrm{MHz})$ spectrometer. NMR acquisition and processing were performed as previously described. ${ }^{2-7)}$ For each sample, 16 scans were recorded with a $90^{\circ}$ pulse and a 60 -s pulse delay, since highprecision qNMR spectra can be attained when the pulse angle is $90^{\circ}$ and the pulse delay time is greater than the quintuple spin-lattice relaxation time $\left(>5 \times T_{1}\right)$. Chemical shifts are represented in ppm values relative to the proton signal of pyridine- $d_{5}(7.55 \mathrm{ppm})$. Integral values of the proton signals were obtained after Fourier transform of the free-induction decay (FID) data (window function: exponential function $\mathrm{BF}=$ $0.12 \mathrm{~Hz}$, zero filling $=1$; trapezoidal function $\mathrm{T} 1=\mathrm{T} 2=0, \mathrm{~T} 3=$ 90, T4=100); and automatic phase correction.

Determination of $1,4-\mathrm{BTMSB}-d_{4}$ Concentration in the qNMR Reference Solution The qNMR reference solution was prepared as previously described. ${ }^{3,4,6)}$ The 1,4-BTMSB$d_{4}$ reference material $(20 \mathrm{mg})$ was dissolved in pyridine$d_{5}(100 \mathrm{~mL})$ to make the qNMR reference solution. The $1,4-\mathrm{BTMSB}-d_{4}$ concentration in the reference solution can be calculated from the accurate weight of 1,4-BTMSB- $d_{4}$ reference material and its purity certified with SI traceability $(99.8 \pm 0.2 \%)$. In this study, the $1,4-\mathrm{BTMSB}-d_{4}$ concentration was accurately confirmed by qNMR using DEP as an internal standard. DEP $(20.0 \mathrm{mg})$ was weighed and dissolved in $4.0 \mathrm{~mL}$ of the qNMR reference solution, and then $0.6 \mathrm{~mL}$ of the mixed solution was sealed in an NMR test tube (4.932-4.970 mm; diameter $\times 8$ in.; Wako Pure Chemical Ind., Ltd.) and subjected to ${ }^{1} \mathrm{H}-\mathrm{NMR}$ measurement. The $1,4-\mathrm{BTMSB}-d_{4}$ concentration in the qNMR reference solution was calculated by using the ratio of the signal integral at $0.23 \mathrm{ppm}\left(1,4-\mathrm{BTMSB}-d_{4}\right)$ to that at $4.34 \mathrm{ppm}(\mathrm{DEP})$ :

$$
\begin{aligned}
& C_{\mathrm{BTMSB}} \\
& \quad=W_{\mathrm{DEP}} \times \frac{P_{\mathrm{DEP}}}{100} \times\left(\frac{M_{\mathrm{BTMSB}} \times I_{\mathrm{BTMSB}}}{H_{\mathrm{BTMSB}}} / \frac{M_{\mathrm{DEP}} \times I_{\mathrm{DEP}}}{H_{\mathrm{DEP}}}\right)
\end{aligned}
$$


where $C_{\mathrm{BTMSB}}$ is the accurate concentration $(\mathrm{mg} / \mathrm{mL})$ of $1,4-\mathrm{BTMSB}-d_{4}$ in the qNMR reference solution; $W_{\mathrm{DEP}}$ is the concentration $(\mathrm{mg} / \mathrm{mL})$ of the reference material DEP in the mixed solution; $P_{\mathrm{DEP}}$ is the certified purity $(99.98 \%)$ of DEP in the reference material DEP; $M_{\mathrm{BTMSB}}$ and $M_{\mathrm{DEP}}$ are the molecular weights of 1,4-BTMSB- $d_{4}$ and DEP (226.50, 222.24, respectively); $I_{\mathrm{BTMSB}}$ and $I_{\mathrm{DEP}}$ are the signal integrals at $0.23 \mathrm{ppm}\left(1,4-\mathrm{BTMSB}-d_{4}\right)$ and $4.34 \mathrm{ppm}$ (DEP), respectively; and $H_{\mathrm{BTMSB}}$ and $H_{\mathrm{DEP}}$ are the number of protons producing the signal at $0.23 \mathrm{ppm}\left(1,4-\mathrm{BTMSB}-d_{4}, \mathrm{CH}_{3} \times 6\right)$ and $4.34 \mathrm{ppm}$ (DEP, $\mathrm{CH}_{2} \times 2$ ).

Quantitative Determination of Stevioside and Rebaudioside A by qNMR Commercial standards of stevioside (STD-I through -V) and rebaudioside A (RBDA-I through -V) were dried at $105^{\circ} \mathrm{C}$ for $2 \mathrm{~h}$, according to the preparation method of the standard described in the JECFA specifications, ${ }^{1)}$ and then $20 \mathrm{mg}$ of each standard was accurately weighed and dissolved individually in $1.0 \mathrm{~mL}$ of the qNMR reference solution and subjected to ${ }^{1} \mathrm{H}-\mathrm{NMR}$ measurement. The purities $(\% \mathrm{w} / \mathrm{w})$ of stevioside and rebaudioside $\mathrm{A}$ in the standards were calculated from Eq. 2:

$$
\begin{aligned}
& P_{\mathrm{STD} \text { (or RBDA })} \\
&= C_{\mathrm{BTMSB}} \\
& \times\left(\frac{M_{\mathrm{STD}(\text { or RBDA })} \times I_{\mathrm{STD} \text { (or RBDA })}}{H_{\mathrm{STD}(\text { or RBDA })}} / \frac{M_{\mathrm{BTMSB}} \times I_{\mathrm{BTMSB}}}{H_{\mathrm{BTMSB}}}\right) \\
& \times \frac{100}{W_{\mathrm{STD}(\text { or RBDA })}}
\end{aligned}
$$

where $P_{\mathrm{STD} \text { (or RBDA) }}$ is the purity $(\% \mathrm{w} / \mathrm{w})$ of stevoside (or rebaudioside A) in the commercial standard; $C_{\mathrm{BTMSB}}$ is the accurate concentration $(\mathrm{mg} / \mathrm{mL})$ of $1,4-\mathrm{BTMSB}-d_{4}$ in the qNMR reference solution; $M_{\mathrm{STD} \text { (or RBDA) }}$ and $M_{\mathrm{BTMSB}}$ are the molecular weights 804.9 (or 967.0) and 226.50, respectively; $I_{\mathrm{STD}}$ (or RBDA) and $I_{\mathrm{BTMSB}}$ are the signal integrals at 5.68 or $2.71 \mathrm{ppm}$ (stevioside) or 5.31 or $2.65 \mathrm{ppm}$ (rebaudioside A) and $0.23 \mathrm{ppm}$ $\left(1,4-\mathrm{BTMSB}-d_{4}\right)$, respectively; $H_{\mathrm{STD}}$ (or RBDA) and $H_{\mathrm{BTMSB}}$ are the number of protons producing the signal at 5.68 or $2.71 \mathrm{ppm}$ (stevioside, $\mathrm{CH} \times 1$ each) [or at 5.31 or $2.65 \mathrm{ppm}$ (rebaudioside $\mathrm{A}, \mathrm{CH} \times 1$ each)] and $0.23 \mathrm{ppm}\left(1,4-\mathrm{BTMSB}-d_{4}, \mathrm{CH}_{3} \times 6\right)$; and $W_{\text {STD (or RBDA) }}$ is the concentration $(\mathrm{mg} / \mathrm{mL}$ ) of stevioside (or rebaudioside $\mathrm{A}$ ) in the commercial standard. In this study, an analytical software package for quantification, ALICE 2 for qNMR (JEOL RESONANCE, Tokyo), was employed to automatically calculate the purity of the stevioside and rebaudioside $\mathrm{A}$ in the samples from the qNMR FID data.

LC Analysis of Stevioside and Rebaudioside A Aliquots $(40 \mu \mathrm{L})$ of the solutions prepared for qNMR were dried under $\mathrm{N}_{2}$ gas and then dissolved in $1.6 \mathrm{~mL}$ of $\mathrm{CH}_{3} \mathrm{CN}$-water $(30: 70$ $\mathrm{v} / \mathrm{v})$. The solutions $(5 \mu \mathrm{L})$ were subjected to $\mathrm{LC}$ analysis, and the peak areas were measured. The LC system was an Alliance 2695 with a 2996 photodiode array detector (Waters Co., Massachusetts, U.S.A.), and the analysis conditions were as follows: LC column: Capcell Pak C18 MG (4.6 mm i.d. $\times 250 \mathrm{~mm}, 5 \mu \mathrm{m}$, Shiseido Co., Ltd., Tokyo, Japan); column temperature, $40^{\circ} \mathrm{C}$; flow rate, $1 \mathrm{~mL} / \mathrm{min}$; mobile phase, $\mathrm{CH}_{3} \mathrm{CN}$-ammonium formate $(5 \mathrm{~mm}, \mathrm{pH} 6.1,32: 68 \mathrm{v} / \mathrm{v}$, isocratic elution); detection wavelength, $210 \mathrm{~nm}$. Each solution was injected in duplicate.

\section{Results and Discussion}

Selection of ${ }^{1} \mathrm{H}-\mathrm{NMR}$ Target Signals for Quantification by qNMR The ${ }^{1} \mathrm{H}-\mathrm{NMR}$ spectra of stevioside, rebaudioside $\mathrm{A}$, and six other steviol glycosides (rebaudiosides B, C, and D; steviolbioside; dulcoside $\mathrm{A}$; and rubusoside) recorded in pyridine- $d_{5}$ are shown in Fig. 3. Proton signals of stevioside and rebaudioside $\mathrm{A}$ were assigned based on the chemical shifts in previous reports. ${ }^{8,9)}$ The $5.68 \mathrm{ppm}(\mathrm{H}-17 \alpha)$ and $2.71 \mathrm{ppm}$ $(\mathrm{H}-14 \alpha)$ signals of stevioside and the $5.31 \mathrm{ppm}\left(\mathrm{H}-1^{\prime \prime \prime \prime}\right)$ and $2.65 \mathrm{ppm}(\mathrm{H}-14 \alpha)$ signals of rebaudioside A could be distinguished. Rebaudiosides B and D showed signals at chemical shifts similar to the $5.68 \mathrm{ppm}(\mathrm{H}-17 \alpha)$ signal of stevioside, and rebaudioside D and rubusoside showed signals at chemical shifts similar to the $2.71 \mathrm{ppm}(\mathrm{H}-14 \alpha)$ signal of stevioside. Rebaudioside $\mathrm{C}$ and dulcoside A showed signals at chemical shifts similar to the $2.65 \mathrm{ppm}(\mathrm{H}-14 \alpha)$ signal of rebaudioside A. Steviolbioside showed signals at chemical shifts similar to the $5.31 \mathrm{ppm}\left(\mathrm{H}-1^{\prime \prime \prime \prime}\right)$ signal of rebaudioside A. However, the contents of rebaudiosides $\mathrm{B}$ and $\mathrm{D}$ and rubusoside in the stevioside standards and of rebaudioside $\mathrm{C}$, dulcoside $\mathrm{A}$ and steviolbioside in the rebaudioside A standards were very low by LC/ UV analysis, less than 0.17 area $\%$ (data not shown). Therefore, each of the above two signals of stevioside $(5.68,2.71 \mathrm{ppm})$ and rebaudioside $\mathrm{A}(5.31,2.65 \mathrm{ppm})$ was not affected by the signals arising from other steviol glycosides in the standards. Thus, the above four signals of stevioside and rebaudioside A were selected as target signals for qNMR.

In the present study, 1,4-BTMSB- $d_{4}$ (Fig. 3) was used as an internal standard for $\mathrm{qNMR},{ }^{3,4,6)}$ because the $1,4-\mathrm{BTMSB}-d_{4}$ signal $(0.23 \mathrm{ppm})$ does not overlap with any signals arising from steviol glycosides and because we can accurately calculate the $1,4-\mathrm{BTMSB}-d_{4}$ concentration in the prepared qNMR reference stock solution from the certified purity $(99.8 \pm 0.2 \%)$ with SI traceability. Thus, the qNMR method allows the absolute quantification of stevioside and rebaudioside $\mathrm{A}$ because the purity of 1,4 -BTMSB- $d_{4}$ used as the internal standard is accurately known.

Confirmation of Linearity of qNMR-Quantified Values of Stevioside and Rebaudioside A In this study, 20 mg/ $\mathrm{mL}$ standards were used in the tests to determine the purity of stevioside and rebaudioside A because weights less than $10 \mathrm{mg}$, as measured by a semi-microbalance, showed an uncertainty of greater than $0.2 \%$. In the concentration range around $20 \mathrm{mg} / \mathrm{mL}(15-35 \mathrm{mg} / \mathrm{mL})$, the linearity between the weight of the tested standards and the quantified levels of stevioside or rebaudioside A determined by $\mathrm{qNMR}$ could be investigated. As shown in Fig. 4a, using the ratios of the signal integrals at $5.68 \mathrm{ppm}(\mathrm{H}-17 \alpha)$ and $2.71 \mathrm{ppm}(\mathrm{H}-14 \alpha)$ of stevioside to that of $1,4-\mathrm{BTMSB}-d_{4}$, the amount of stevioside determined by qNMR correlated $\left(R^{2}=0.9989\right)$ with the weights of the stevioside standard. The amount of rebaudioside A determined by qNMR also correlated $\left(R^{2}=0.9996,0.9985\right)$ with the weights of the rebaudioside A standard (Fig. 4b). These results showed the linearity between the weight of the tested standards and the quantified levels of stevioside or rebaudioside A by qNMR, suggesting that no calibration curves are necessary in the $15-35 \mathrm{mg} / \mathrm{mL}$ range. In Fig. 4 , the slopes of the regression lines were $0.97-0.98$, reflecting the purities of the stevioside or rebaudioside $\mathrm{A}$ in the standards. Using the two signals, quantitation levels due to the different protons of the compounds were comparable. 


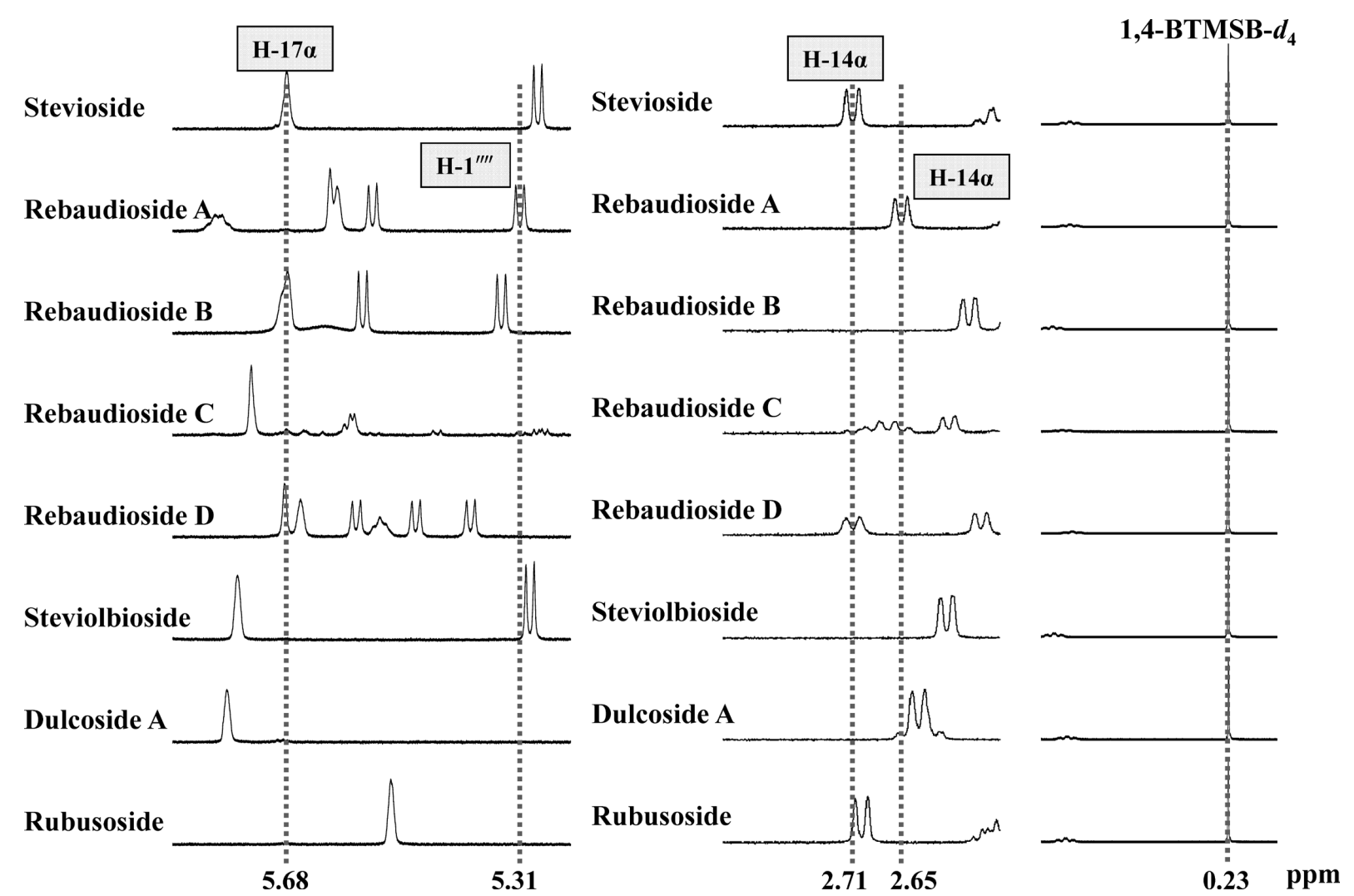

Fig. 3. qNMR Spectra of Steviol Glycosides

The spectra were obtained using a qNMR solution (pyridine- $d_{5}$ ) containing 1,4-BTMSB- $d_{4}$. Square labels indicate the proton positions of the signals of stevioside or rebaudioside A, as shown in Fig. 1 .

(a)

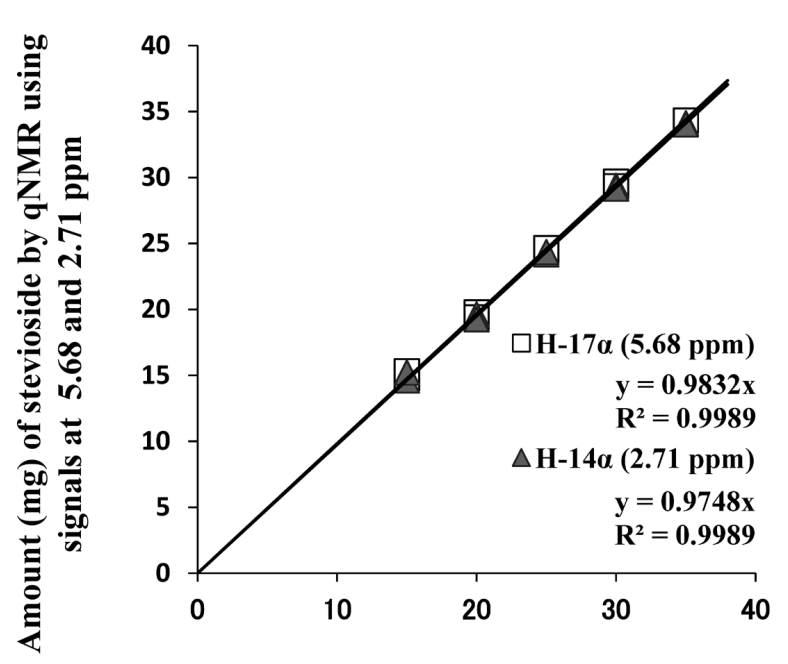

Reagent weight (mg) (b)

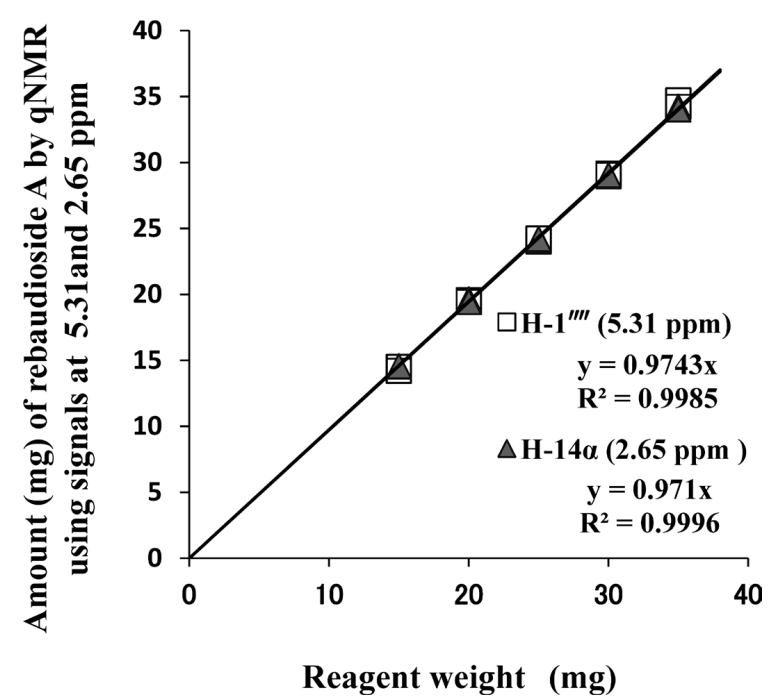

Fig. 4. Relationship between Reagent Weight and Amount of Stevioside or Rebaudioside A Determined by qNMR

The utility of qNMR for quantifying stevioside and rebaudioside A in the range of about $15-35 \mathrm{mg} / \mathrm{mL}$ of (a) STD-I and (b) RBDA-II was investigated.

Determination by qNMR of Stevioside and Rebaudioside A Purities in Various Commercial Standards The absolute purities of stevioside and rebaudioside $\mathrm{A}$ in five commercial standards after drying at $105^{\circ} \mathrm{C}$ for $2 \mathrm{~h}$ were determined by the qNMR method using the same internal standard. As shown in Table 1, the relative standard deviations of three trials were $0.2-1.1 \%$. The values determined from the two signals, $5.68 \mathrm{ppm}(\mathrm{H}-17 \alpha)$ and $2.71 \mathrm{ppm}(\mathrm{H}-14 \alpha)$ for stevioside and
$5.31 \mathrm{ppm}\left(\mathrm{H}-1^{\prime \prime \prime \prime}\right)$ and $2.65 \mathrm{ppm}(\mathrm{H}-14 \alpha)$ for rebaudioside $\mathrm{A}$, correlated well. Therefore, it appears that no remarkable signal arose from the overlap of the impurity to the signals for quantification. Thus, the averages of the purities were calculated from the two values derived from each of the two signals of stevioside and rebaudioside A, after confirming the similarity of the two values.

By qNMR, the purities of stevioside were $92.0-97.7 \%$ and 
those of rebaudioside A were 94.6-96.6\% in each of the five commercial standards (Fig. 5). The purities of STD-IV and STD-V were approximately $5 \%$ lower than that of STD-I, and the purities of RBDA-III, -IV, and -V were approximately $1-2 \%$ lower than that of RBDA-II. The qNMR-determined purity of stevioside and rebaudioside $\mathrm{A}$ in the standards was generally lower than that claimed in the product literature by

Table 1. Purity Determination of Stevioside (a) and Rebaudioside A (b) in the Different Standards by qNMR and LC

(a)

\begin{tabular}{lccc}
\hline Name & $\begin{array}{c}\text { Purity (\%) by } \\
\text { qNMR }^{a)}\end{array}$ & $\begin{array}{c}\text { Purity (\%) by } \\
\text { LC } \\
\text { (b) } \\
\text { using STD-I standard }\end{array}$ & $\begin{array}{c}\text { Purity (\%) by LC } \text { LC }^{c} \\
\text { standard }\end{array}$ \\
\hline Stevioside & & & \\
STD-I & $97.7 \pm 1.0$ & - & $98.0 \pm 1.5$ \\
STD-II & $95.7 \pm 0.3$ & $95.2 \pm 0.7$ & $95.5 \pm 0.7$ \\
STD-III & $95.9 \pm 0.4$ & $96.1 \pm 0.3$ & $96.4 \pm 0.3$ \\
STD-IV & $92.0 \pm 0.5$ & $91.7 \pm 0.9$ & - \\
STD-V & $92.0 \pm 0.7$ & $92.3 \pm 0.4$ & $92.5 \pm 0.4$ \\
\hline
\end{tabular}

a) AV \pm S.D., $n=3$; the average of the values determined from the two signals, $5.68 \mathrm{ppm}(\mathrm{H}-17 \alpha)$ and $2.71 \mathrm{ppm}(\mathrm{H}-14 \alpha)$. b) $\mathrm{AV} \pm$ S.D., $n=3$; the purity value of STD-I determined by qNMR was used for calculation. c) AV \pm S.D., $n=3$; the purity value of STD-IV determined by qNMR was used for calculation.

(b)

\begin{tabular}{lccc}
\hline \multicolumn{1}{c}{ Name } & $\begin{array}{c}\text { Purity (\%) by } \\
\text { qNMR }^{a}\end{array}$ & $\begin{array}{c}\text { Purity (\%) by } \\
\text { LC }^{b)} \begin{array}{c}\text { Purity (\%) by LC } \\
\text { as standard }\end{array}\end{array}$ & $\begin{array}{c}\text { using STD-IV as } \\
\text { standard }\end{array}$ \\
\hline Rebaudioside A & & & \\
RBDA-I & $96.3 \pm 0.3$ & $96.7 \pm 0.6$ & $96.3 \pm 0.6$ \\
RBDA-II & $96.6 \pm 0.2$ & - & $96.2 \pm 1.0$ \\
RBDA-III & $95.0 \pm 0.6$ & $95.1 \pm 1.1$ & $94.7 \pm 1.1$ \\
RBDA-IV & $94.6 \pm 0.7$ & $95.0 \pm 1.0$ & - \\
RBDA-V & $94.9 \pm 0.4$ & $95.3 \pm 1.0$ & $94.9 \pm 1.0$ \\
\hline
\end{tabular}

a) $\mathrm{AV} \pm$ S.D., $n=3$; the average of the values determined from the two signals, $5.31 \mathrm{ppm}\left(\mathrm{H}-1^{\prime \prime \prime \prime}\right)$ and $2.65 \mathrm{ppm}(\mathrm{H}-14 \alpha)$. b) AV \pm S.D., $n=3$; the purity value of RBDA-II determined by qNMR was used for calculation. c) AV \pm S.D., $n=3$; the purity value of RBDA-IV determined by qNMR was used for calculation.

(a)

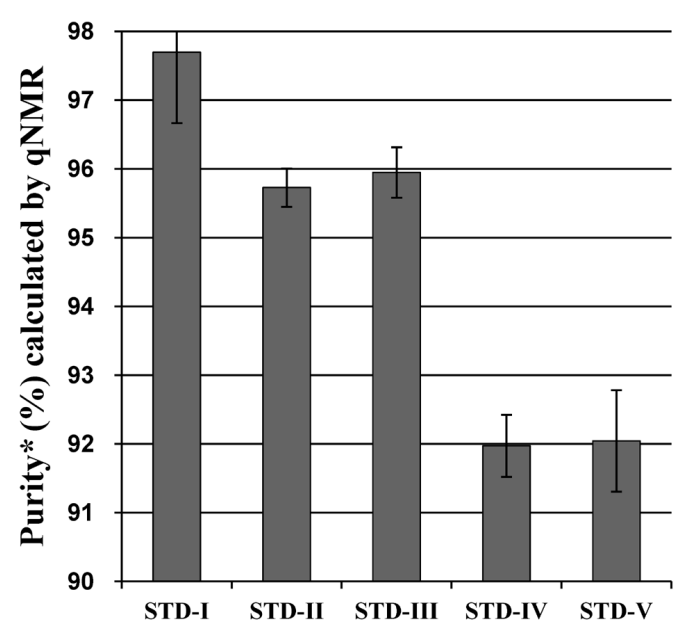

*Average purity calculated from the $[17 \alpha]$ and $[14 \alpha]$ signals

**Average purity calculated from the $\left[1^{\prime \prime \prime \prime}\right]$ and $[14 \alpha]$ signals manufacturers. This suggests that impurities or solvents that do not have UV absorbance might be present in the tested standards, and thus were not detected by LC/UV analysis. If the claimed purity of a commercial standard is different from the actual purity and if the claimed value is employed in the quantitative analysis of a sample, the quantitated contents of the stevioside and rebaudioside A of the sample will be incorrect. Thus, it is very important to confirm the accurate purity of stevioside and rebaudioside A in quantification standards.

Recently, Pieri et al. reported ${ }^{10)}$ a quality control method for stevia extract products based on qNMR. Their method is very useful, but an NMR apparatus is necessary. In this study, an absolute quantification method employing qNMR was applied to determine the purities of stevioside and rebaudioside $\mathrm{A}$ in their commercial standards. By using standards with accurate purities determined by SI-traceable qNMR, the stevioside and rebaudioside $\mathrm{A}$ in various stevia extracts can be accurately quantified by various analytical methods such as LC.

Comparison of Results Obtained from qNMR and LC/ UV Peak Areas Aliquots of solutions prepared for the qNMR of each of the five standards of stevioside and rebaudioside A $(20 \mathrm{mg} / \mathrm{mL}, n=3)$ and those of STD-I and RBDA-II $(15,25 \mathrm{mg} / \mathrm{mL}, n=2)$ were used for LC analysis, and the peak areas were measured. Then, the purities of stevioside and rebaudioside $\mathrm{A}$ in commercial standards determined by qNMR were compared to their peak areas at $210 \mathrm{~nm}$ by LC/UV analysis. As shown in Fig. 6, the LC peak areas of stevioside and rebaudioside A correlated (stevioside: $R^{2}=0.994, y=523.04 x$; rebaudioside A: $R^{2}=0.994, y=437.25 x$ ) with the amounts determined by our qNMR method. Based on the ratio of the slopes of the regression lines for stevioside and rebaudioside A in Fig. 6, the accurate relative ratio of absorbance at $210 \mathrm{~nm}$ for stevioside to that for rebaudioside $\mathrm{A}$ in the same amounts was calculated as $1.20(=523.04 / 437.25)$. These results suggest that the accurate relative ratio of absorbance between the same amounts of the different compounds can be calculated by a combination of qNMR and LC/UV analysis.

(b)

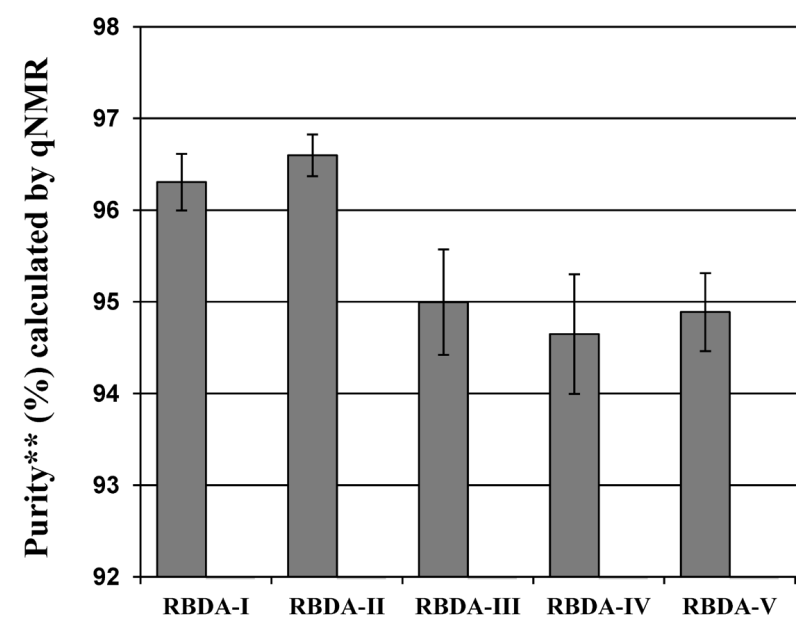

Fig. 5. Purity Determination of (a) Stevioside and (b) Rebaudioside A in the Different Standards by qNMR 


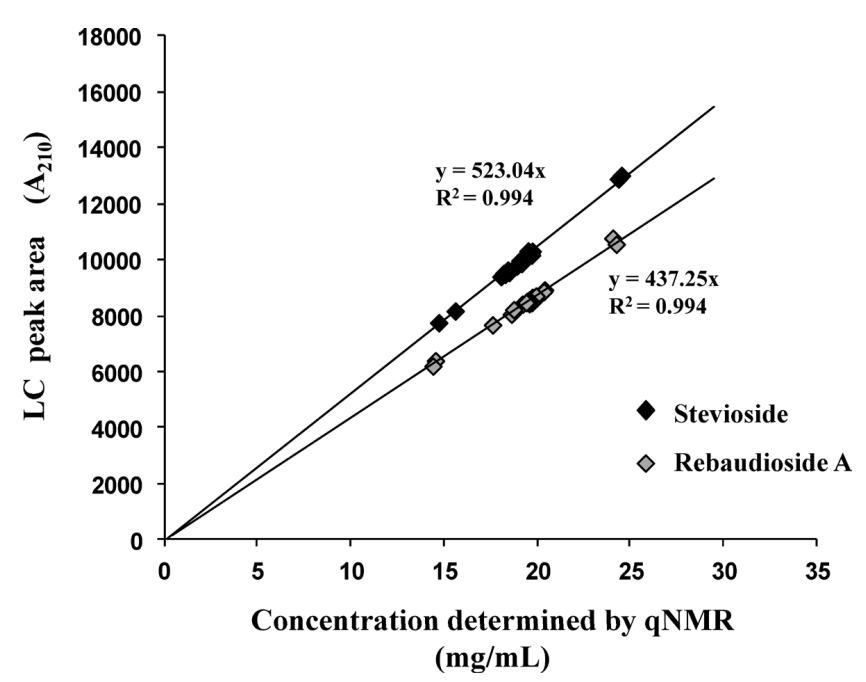

Fig. 6. Relationship between the Concentration of Stevioside or Rebaudioside A Determined by qNMR and Peak Areas at $210 \mathrm{~nm}$

Signals at 2.71 and $5.68 \mathrm{ppm}$ were used for the stevioside calculation, and signals at 2.65 and $5.31 \mathrm{ppm}$ were used for the rebaudioside A calculation.

Table 1 shows the purities of stevioside and rebaudioside $\mathrm{A}$ in the different standards determined by qNMR and by LC using two of them as quantification standards. For the LC determination, the purities of each of the two quantification standards determined by qNMR were utilized for calculation. As shown in Table 1, the purities determined by qNMR and those determined by LC were similar, and the differences between then were $0.03-0.5 \%$. These results suggest that the accurate quantification of a compound can be achieved by LC analysis if the purity of the quantification standard is determined by qNMR with SI traceability and is used for the LC/ UV analysis.

\section{Conclusion}

Using 1,4-BTMSB- $d_{4}$ reference material with SI traceability as an internal standard, we utilized qNMR to examine the absolute purity of stevioside and rebaudioside A in commercial standards. The purities of stevioside and rebaudioside $\mathrm{A}$ in each of five commercial standards were precisely determined, and they correlated well with their peak areas obtained by $\mathrm{LC} / \mathrm{UV}$ analysis. These results demonstrate that the qNMR method is useful for determining the purity of stevioside and rebaudioside $\mathrm{A}$ in commercial standards. In addition, these findings suggest that we can accurately quantify stevioside and rebaudioside $\mathrm{A}$ in various stevia extracts by LC using standard reagents whose purity has been accurately identified by qNMR.

Acknowledgments We are grateful to Dr. J. Iwamura, Laboratory of Creative Science, Ltd., Wako Pure Chemical Industries, Ltd., Maruzen Pharmaceuticals, Ltd., Morita Kagaku Kogyo, Ltd., and the Japan Food Additives Association for providing commercially unavailable steviol glycosides and stevia extract samples. The qNMR method utilized in this study was developed collaboratively. We would like to thank our collaborators, Dr. T. Saito and Dr. T. Ihara, National Metrology Institute of Japan (AIST); Dr. Y. Yoshida, Wako Pure Chemical Industries, Ltd.; and Dr. R. Koike and Dr. T. Horinouchi of Kao, Ltd. This study was supported by a Grantin-Aid for Scientific Research from the Ministry of Health, Welfare and Labour of Japan.

\section{References}

1) Joint FAO/WHO Expert Committee on Food Additives (JECFA), Compendium of Food Additive Specifications. Monograph 10. "Steviol glycosides.”: 〈http://www.fao.org/ag/agn/jecfa-additives/specs/ monograph10/additive-442-m10.pdf), cited 5 January, 2012.

2) Saito T., Ihara T., Koike M., Kinugasa S., Fujimine Y., Nose K., Hira T., Accred. Qual. Assur., 14, 79-86 (2009).

3) Tahara M., Sugimoto N., Suematsu T., Arifuku K., Saito T., Ihara T., Yoshida Y., Tada A., Kubota R., Shimizu K., Yamazaki T., Tanamoto K., Nakazawa H., Nishimura T., Jpn. J. Food Chem. Safety, 16, 28-33 (2009).

4) Sugimoto N., Tada A., Suematsu T., Arifuku K., Saito T., Ihara T., Yoshida Y., Kubota R., Tahara M., Shimizu K., Ito S., Yamazaki T., Kawamura Y., Nishimura T., Food Hyg. Saf. Sci., 51, 19-27 (2010).

5) Sugimoto N., Tada A., Suematsu T., Arifuku K., Saito T., Ihara T., Yoshida Y., Tahara M., Kubota R., Shimizu K., Yamazaki T., Kawamura Y., Nishimura T., Jpn. J. Food Chem. Safety, 17, 179184 (2010).

6) Tada A., Takahashi K., Sugimoto N., Suematsu T., Arifuku K., Saito T., Ihara T., Yoshida Y., Ishizuki K., Nishimura T., Yamazaki T., Kawamura Y., Food Hyg. Saf. Sci., 51, 205-212 (2010).

7) Hosoe J., Sugimoto N., Goda Y., Pharm. Med. Device Regul. Sci., 41, 960-970 (2010).

8) Calsteren M.-R. V., Bussière Y., Bissonnette M. C., Spectroscopy, 11, 143-156 (1993).

9) Steinmetz W. E., Lin A., Carbohydr. Res., 344, 2533-2538 (2009).

10) Pieri V., Belancic A. D., Morales S., Stuppner H., J. Agric. Food Chem., 59, 4378-4384 (2011). 